\title{
CORRIGENDUM
}

\section{Ultrastructure observation on the cells at different life history stages of Cryptocaryon irritans (Ciliophora: Prostomatea), a parasitic ciliate of marine fishes - CORRIGENDUM}

RUI MA, BING NI, XINPENG FAN*, ALAN WARREN, FEI YIN* and FUKANG GU doi:10.1017/S0031182016001074, Published by Cambridge University Press, 17 June 2016.

The authors apologise for errors in the Corresponding author information in the footnote on page 1 of the article. There should be two corresponding authors belonging to two institutions. Therefore the footnote should read as follows:

* Corresponding authors: X. Fan, 500 Dongchuan Road, 200241, Shanghai, China. Tel: +86 2154345473. Fax: +86 21 54341006. E-mail: xpfan@bio.ecnu.edu.cn; F. Yin, Room 316, Building 6, 300 Jungong Road, 200090, Shanghai, China. Tel: +86 21 65664854. Fax: +86 21 65683926. E-mail: yinf@ecsf.ac.cn

REFERENCE

Rui Ma, Bing Ni, Xinpeng Fan, Alan Warren, Fei Yin and Fukang Gu. Ultrastructure observation on the cells at different life history stages of Cryptocaryon irritans (Ciliophora: Prostomatea), a parasitic ciliate of marine fishes. Parasitology. Published by Cambridge University Press, 17 June 2016. doi:10.1017/S0031182016001074. 